\title{
The Role of The Physical and Social Environment for Physical Activity for College Students During the Covid-19 Pandemic
}

\author{
Melissa Bopp, PhD \\ Pennsylvania State University \\ Oliver W. A. Wilson, PhD \\ Pennsylvania State University \\ Lucas D. Elliott, BS \\ Pennsylvania State University \\ Kelsey E. Holland, MS \\ Pennsylvania State University \\ Michele Duffey, MS \\ Pennsylvania State University
}

\begin{abstract}
Background: The COVID-19 pandemic created significant disruptions for college students, impacting health and physical activity (PA). Changes to the PA environment presented many challenges for students.

Purpose: To examine the influence of the physical and social environment on PA participation for college students during the onset of COVID-19 restrictions.

Methods: This cross-sectional, mixed methods survey used an online questionnaire during the onset of COVID-19 restrictions with a volunteer sample of college students at a large university in the United States. Participants self-reported their demographics, PA level and environment for PA, and responded to an open-ended question about their PA participation during the pandemic. Correlations and independent samples $t$-tests examined relationships between PA and the environment. Qualitative data were scanned to identify overarching themes.

Results: Participants $(n=395)$ were predominantly Non-Hispanic White and female. The neighborhood environment and access to PA equipment were associated with PA for both men and women. Major qualitative themes highlighted the role of the physical environment and PA. Participating in PA with friends and family was positively associated with PA for both men and women as well.
\end{abstract}


Conclusions: This study provides insight on the importance of the social and built environment for encouraging and supporting PA among college students during the COVID-19 pandemic which may provide insight for distance education as higher education evolves.

Submitted 17 March 2021: accepted 22 September 2021

Keywords: college student, physical activity, pandemic, social environment, physical environment

\section{INTRODUCTION}

The COVID-19 pandemic has created significant disruptions in daily life for many around the globe, creating changes to how individuals live, work, learn and interact with each other (World Health Organization, 2020). As the pandemic progressed in the United States, college campuses suspended in person classes for remote instruction (The Chronicle of Higher Education, 2020). This change resulted in many university students relocating from their campus dormitories and housing to other locations, leading to disrupted routines and learning environments with limited access to social support from peers. Health behaviors, such as healthy eating, getting adequate sleep, binge drinking, and physical activity (PA) participation all had the potential to be impacted during this time by the change of location and access to resources.

Although the impact of the pandemic on physical health presented pressing concerns relative to infection and risk of death, the effect of the pandemic on mental health from stress, anxiety, and isolation has been noted in different countries, age groups, and populations (Jakovljevic, Bjedov, Jaksic, \& Jakovljevic, 2020; Talevi et al., 2020). Children and young adults across the globe experienced increased anxiety and depression during periods of lock-down and isolation (Kaparounaki, et al., 2020; Wathelet et al., 2020). Regular PA has notable benefits for anxiety, depression, and better psychological well-being (Physical Activity Guidelines Advisory Committee, 2018). Thus, PA could be protective against the adverse mental health outcomes seen across different groups during the pandemic. Unfortunately, data has suggested that rates of PA declined significantly during this time frame. Objective and selfreport assessments from various countries noted significant declines in PA and increases in sedentary behavior regardless of age and gender (Tison et al., 2020). Among college students specifically, declines in PA were noted in many countries (Barkley et al., 2020; Gallo, Gallo, Young, Moritz, \& Akison, 2020) and possibly mediated by living situation during country-wide lockdowns (Romero-Blanco et al., 2020). Despite the overall decline in PA during the pandemic, those who were active typically experienced improved or stable mental health outcomes (Maher, Hevel, Reifsteck, \& Drollette, 2021; Schuch et al., 2020).

Within a social ecological framework, the physical (e.g., access to places to be active, supportive infrastructure for PA) and social environments (e.g., social support) for PA have long been noted as important influences on PA 
participation (Bauman et al., 2012). The social environment for PA has been found to be influential for many population groups, including college students (Gruber, 2008; King, Vidourek, English, \& Merianos, 2013). A supportive physical environment, which includes the built and natural environment to support both leisure-time PA and active travel (i.e., walking and bicycling for transportation) are noted to promote positive behaviors in the general population and among college students (Peachey \& Baller, 2015). The impact of the physical and social environments on PA during the challenging times of the COVID-19 restrictions has not been well established in the limited research available. Therefore, the purpose of this study was to examine the influence of the physical and social environment on PA participation among a sample of college students during COVID-19 pandemic restrictions.

\section{METHODS}

The design of this study was observational; a cross-sectional, mixed-methods survey using an online questionnaire. Participants provided responses to questions using set responses as well as open-ended questions.

\section{Participants and Setting}

Undergraduate students who were enrolled at a large university in the northeastern United States were recruited to participate in an online survey. Potential participants $(n=720)$ were individuals who enrolled in general education health and wellness classes (200+ sections) during the 2019-2020 academic year and had previously responded to an earlier survey invitation. This university moved all classes to remote instruction in mid-March 2020 due to the pandemic and the survey was conducted in mid-April 2020. The Institutional Review Board at the first author's institution approved this study.

\section{Recruitment}

Students were sent an email with an invitation to participate in an online survey (Qualtrics, Provo, UT) about PA and health. Reminder emails were sent three, six, and 12 days after the first invitation to participants who had not yet responded. Upon opening the survey, students were presented with an informed consent statement. The response rate was $30.69 \%(n=519)$ and the completion rate was $94.61 \%(n=491)$. For the quantitative analyses, only respondents $(n=395)$ with complete demographic, PA, and environment data were included. For qualitative responses, only those who responded to the open-ended question and demographic questions $(n=412)$ were included in the analyses. Participants had different rates of completion for the demographics, PA, environment data, and openended questions, so there were different sample sizes for the two analyses. 


\section{Measures}

Demographics. Participants self-reported their age, year in class (1-10 semester standing), gender (male, female, other gender identity), and race/ethnicity (Non-Hispanic White, Non-Hispanic Black, Hispanic, Asian American/Pacific Islander, Other). Participants reported the five-digit zip code of the location where they were spending time during university mandated remote learning. Those reporting a zip code within a 5-mile radius of the campus were considered as "staying" during this period, which was considered in analyses.

Physical activity behavior. Moderate and vigorous PA and active transportation (walking and bicycling for transportation) were assessed via the Global PA Questionnaire (GPAQ), a valid and reliable form of PA assessment in an adult population (Armstrong \& Bull, 2006). Metabolic Equivalent-minutes/week (MET-mins/week) were calculated for each type of PA. Strength training frequency and duration were assessed with questions similar to the GPAQ (Wilson, Papalia, Duffey, \& Bopp, 2019) and minutes per week of strength training were calculated.

Social environment for PA. The social environment for PA was assessed with three separate items. One item asked people to respond to the question, "The person or people I currently live with are regularly physically active" with a 5-point Likert scale of 1 (strongly disagree) to 5 (strongly agree). An option for Not Applicable/I live by myself was also available for selection. Using the Social Support and Exercise Survey (Sallis, Grossman, Pinski, Patterson, \& Nader, 1987), participants responded to two separate questions "During the past month, indicate how often your (1) family and (2) friends/members of your current residence exercised with me" from 1 (none) to 5 (very often) with an option to indicate does not apply.

Physical environment. The physical environment for PA within respondents' neighborhoods was assessed with five items from the Neighborhood Environment Walkability Scale (NEWS) survey (Cerin, Saelens, Sallis, \& Frank, 2006) which addressed sidewalk quality, crime rate during the day, crime rate at night, seeing others being active, traffic volume, and the addition of three items: (1) perception that men in the neighborhood are active, (2) perception that women in the neighborhood are active, and (3) the belief that there are resources in the neighborhood to be active. Participants used a 5-point scale of 1 (strongly disagree) to 5 (strongly agree) to respond, and items were summed to create a composite score, with adequate reliability $(\alpha=0.73)$.

Open ended. Participants were asked a question with an open text field for responses: "Please describe the changes in your activity level since the COVID-19 Quarantine/Social distancing efforts came into place. Please include any factors that have been particularly helpful and hurtful to your activity level.” 


\section{Analyses}

For quantitative analyses, frequencies and descriptive statistics were used to describe the sample. Since PA participation levels were significantly different by gender, analyses were conducted separately for men $(n=105)$ and women $(n=290)$. Pearson correlations examined the relationship between the PA variables and the social and physical environmental variables. Independent samples $t$-tests examined the differences in PA behaviors based on physical environmental access and effect sizes were calculated (Cohen's d). Analyses were performed with SPSS 26.0 and significance levels were set at $p<0.05$. Qualitative data were scanned to identify overarching themes and a codebook was developed based on a social ecological framework, addressing individual, social, and environmental influences (Creswell, 2007). Two independent coders coded the data, evaluated their responses for discrepancies, and came to consensus on the final codes. Only participants who responded to demographic questions for the qualitative responses were included in the analyses.

\section{RESULTS}

Among the respondents $(n=491)$, those who provided complete responses to the demographics, PA behavior, and environment questions $(n=395)$ were predominantly Non-Hispanic White $(n=303,76.7 \%)$ and female $(n=290$, 73.4\%). Most left the area surrounding the university during the pandemic $(n=290,73.4 \%)$. Further characteristics are noted in Table 1. Men reported a higher body mass index $(p=0.02)$, greater strength training $(p<0.001)$, and active travel $(p=0.001)$ compared to women. Women reported greater participation in PA with family compared to men $(\mathrm{p}=0.02)$. Men also reported greater access to cardio equipment than women $(p=0.03)$. Of the original respondents, most $(n=412,89.4 \%$ ) responded to the demographics and open-ended question about their PA participation since COVID-19. Among those who responded, $n=245$ responded with text that was coded as a physical environment influence and $n=57$ responded with text that was coded as a social environment influence and were included in analyses.

\section{Relationship Between PA Behavior and the Physical Environment}

For men, the neighborhood environment was positively associated with vigorous PA, while for women, the neighborhood environment was positively associated with all four types of PA (Table 2). Access to environmental supports for PA was associated with PA for both men and women (Table 3). Among men, the strongest effect sizes were seen for strength training behavior; less consistent effects were seen for women. For women, access to strength training equipment was associated with greater strength training and moderate and vigorous PA. Having 
access to a yard was also associated with greater moderate PA in women. For men, having access to strength training equipment was associated with greater strength training and active transportation. Access to sports equipment (e.g., balls and nets) was also associated with greater strength training among men.

In the qualitative data, several major themes arose regarding the role of the physical environment and PA during COVID-19 restrictions (Table 4). Many individuals noted the COVID-19 related closures impacted their access for places to be active. One non-Hispanic White woman noted: "Before going to remote learning, I went to the [recreation center] every day and ran outside frequently throughout the week. I live in a small town, so I do not have parks or a gym to go to (they're closed everywhere anyways)." Others noted how the closures impacted the type of activities they would do, "All the pools are closed and as a swimmer, that was my main source of exercise. I walk just under 3 miles now most days and am trying to get into running. Doing a virtual 5k on May 1st through campus rec. Don't have a bench to do weight-lifting though do have weights for non-bench activities" (non-Hispanic White Woman). Students also noted that they are doing other types of PA based on what was available in their environment (e.g., running when trails were accessible, etc.).

Like the quantitative findings, participants noted the importance of their neighborhood as an influence on PA. One woman noted the difference between when she was at college compared to at home, "Where I live is very rural so unlike [college town], you can't walk everywhere and there are no sidewalks but there are parks you just have to drive there." As noted in the quantitative data, participants' lack of access to specific resources for PA impacted their ability to do specific types of activity. A Hispanic man noted, "At my house and in my neighborhood there aren't many places where I can exercise. Running is difficult because everything is uphill, strength is difficult because I don't have access to any machines, and just being at home takes away my will to exercise." One non-Hispanic White woman mentioned how the lack of walking for transport was impacting her activity levels, "At school, I typically walk 2-3 miles a day in addition to utilizing the on-campus fitness classes 2-3 times a week. I prefer working out in a class because it helps me stay motivated and I feel I get a better workout. I also do not like working out outside because the weather affects my performance and I don't really like my neighbors to see. But I don't have much space in my house, and I am left to my own devices for working out so it has proven to be very difficult."

\section{Relationship Between PA Behavior and the Social Environment}

Among men, relationships between the social environment and PA were noted (Table 2). Participating in PA with family was positively associated with moderate PA and vigorous PA. For women, participating in PA with friends was associated with moderate and vigorous PA as well as active transportation (walking and biking for 
transportation). Participating in PA with family was associated with greater moderate PA and perceiving that their roommates were active was associated with greater moderate and vigorous PA.

The qualitative data (Table 4) revealed that the social environment was less frequently mentioned as an influence on PA than the physical environment. Having pets (specifically dogs) to walk, was often noted as a frequent activity. In line with the quantitative data, many participants also noted that having friends and/or family to exercise with was a positive factor. One woman noted, "I'm not walking around as much nor for as long (distance wise) as I would at [college]. However, I have been able to go running roughly twice a week for 30-40 minutes and take walks with my parents (which gets them out of the house). I also do more yardwork which is definitely helping me." Some also noted that family and friends could be a barrier, especially with particular activities, "Having family around constantly makes me quite self-conscious so I haven't been motivated to do yoga” (non-Hispanic Black Woman). A lack of social support, mostly from friends was also frequently noted; "My friends and I had the best gym routine for cardio, then weights. It was fun to work out and made the time pass quickly. Now I have no motivation to do it by myself' (Asian American Woman). 
Table 1

Sample Characteristics for the Quantitative Analyses ( $\mathrm{n}=395$ )



Note. ${ }^{*} \mathrm{p}<.05 ; * * * \mathrm{p}<.001$ between males and females. 
Table 2

Pearson Correlations ( $\mathrm{r}$ ) Between the Social and Physical Environment and PA Behavior

\begin{tabular}{|c|c|c|c|c|}
\hline & & & Strength & Active \\
\hline & Moderate PA & Vigorous PA & Training & Transportation \\
\hline \multicolumn{5}{|l|}{$\operatorname{Men}(n=105)$} \\
\hline \multicolumn{5}{|l|}{ Social environment } \\
\hline Participate in PA with Friends & $0.16(p=0.12)$ & $0.16(p=0.14)$ & $0.14(p=0.17)$ & $0.01(p=0.93)$ \\
\hline Participate in PA with Family & $0.27(p=0.01)$ & $0.30(\mathrm{p}=0.004)$ & $0.20(p=0.06)$ & $0.21(p=0.05)$ \\
\hline Perception of activity of roommates & $0.18(\mathrm{p}=0.08)$ & $0.23(\mathrm{p}=0.02)$ & $0.12(p=0.23)$ & $0.13(p=0.22)$ \\
\hline \multicolumn{5}{|l|}{ Physical activity environment } \\
\hline Neighborhood summary score & $0.19(p=0.06)$ & $0.21(p=0.04)$ & $0.09(p=0.35)$ & $0.16(p=0.11)$ \\
\hline \multicolumn{5}{|l|}{ Women $(n=290)$} \\
\hline \multicolumn{5}{|l|}{ Social environment } \\
\hline Participate in PA with Friends & $0.25(\mathrm{p}<0.001)$ & $0.13(\mathrm{p}=0.03)$ & $0.04(p=0.48)$ & $0.16(p=0.01)$ \\
\hline Participate in PA with Family & $0.35(\mathrm{p}<0.001)$ & $0.10(\mathrm{p}=0.08)$ & $0.11(p=0.06)$ & $0.03(p=0.64)$ \\
\hline Perception of activity of roommates & $0.25(\mathrm{p}<0.001)$ & $0.16(p=0.006)$ & $0.09(p=0.11)$ & $0.11(p=0.08)$ \\
\hline \multicolumn{5}{|l|}{ Physical activity environment } \\
\hline Neighborhood summary score & $0.25(\mathrm{p}<0.001)$ & $0.15(\mathrm{p}=0.01)$ & $0.13(p=0.03)$ & $0.15(\mathrm{p}=0.01)$ \\
\hline
\end{tabular}

Note. Bolded $\mathrm{p}$ values $=$ significant relationships between the social environment and PA. 
Table 3

Comparison of $\mathrm{P} A$ Behavior by Type of Environmental Access

\begin{tabular}{|c|c|c|c|c|c|c|c|c|c|c|c|c|c|c|c|c|}
\hline & \multicolumn{3}{|c|}{ cardio equipment access } & \multicolumn{5}{|c|}{ strength training equipment access } & \multicolumn{3}{|c|}{ yard access } & \multicolumn{5}{|c|}{ sports equipment access } \\
\hline & yes & no & $\mathrm{t}$ & $\mathrm{d}$ & yes & no & $\mathrm{t}$ & $\mathrm{d}$ & yes & no & $\mathrm{t}$ & $\mathrm{d}$ & yes & no & $\mathrm{t}$ & $\mathrm{d}$ \\
\hline \multicolumn{17}{|c|}{ Males $(\mathrm{n}=105)$} \\
\hline \multirow[b]{2}{*}{ Moderate PA } & 115.04 & 107.40 & & & 110.37 & 112.71 & & & 111.44 & 111.21 & & & 117.30 & 102.41 & & \\
\hline & $(129.88)$ & (131.33) & 0.59 & 0.05 & $(136.67)$ & $(122.06)$ & 0.09 & 0.01 & $(121.69)$ & $(151.09$ & 0.01 & 0 & $(140.26)$ & $(113.80)$ & 0.55 & 0.11 \\
\hline Vigorous PA & $(150.01)$ & $(117.04)$ & 0.63 & 0.13 & $(142.67)$ & $(121.89)$ & 1.39 & 0.29 & $(143.05)$ & $(115.27)$ & 0.56 & 0.13 & $(148.10)$ & (114.74) & 0.93 & 0.19 \\
\hline Strength & 105.57 & 70.93 & & & 127.37 & 37.52 & $3.62^{* *}$ & & 90.22 & 88.14 & & & 112.62 & 56.56 & & \\
\hline Training & (133.13) & $(124.80)$ & 1.33 & 0.27 & $(150.26)$ & $(67.46)$ & * & 0.77 & (126.54) & $(140.50)$ & 0.07 & 0.02 & $(149.97)$ & $(85.08)$ & $2.16^{*}$ & 0.45 \\
\hline Active & 61.15 & 53.78 & & & 53.32 & 63.85 & & & 62.19 & 45.92 & & & 59.52 & 55.00 & & \\
\hline Transport & (109.94) & (101.59) & 0.34 & 0.07 & $(104.04)$ & $(108.76)$ & 0.49 & 0.1 & (106.54) & (104.08) & 0.68 & 0.15 & (111.48) & (97.88) & 0.21 & 0.04 \\
\hline \multirow{3}{*}{ Moderate PA } & 149.89 & 134.02 & & & 154.77 & 122.22 & & & 151.75 & 113.15 & 2.17 & & 151.15 & 127.19 & & \\
\hline & $(146.26)$ & $(126.80)$ & 0.95 & 0.12 & (144.58) & (120.14) & $2 *$ & 0.25 & (134.46) & (132.48) & * & 0.29 & (134.31) & (135.32) & 1.46 & 0.18 \\
\hline & 129.20 & 107.88 & & & 138.45 & 91.04 & & & 126.62 & 90.59 & & & 116.26 & 117.53 & & \\
\hline Vigorous PA & (146.96) & $(142.57)$ & 1.21 & 0.15 & (145.35) & $(139.82)$ & $2.74 * *$ & 0.33 & (150.94) & (123.77) & 1.87 & 0.26 & $(144.52)$ & $(145.17)$ & 0.07 & 0.01 \\
\hline Strength & 56.59 & 46.29 & & & & 23.86 & $5.43^{* *}$ & & 52.61 & 45.14 & & & 52.74 & 47.76 & & \\
\hline Training & $(81.87)$ & $(78.22)$ & 1.06 & 0.12 & $73.46(94.51)$ & $(45.17)$ & * & 0.66 & $(79.85)$ & $(79.32)$ & 0.71 & 0.09 & $(79.99)$ & $(79.71)$ & 0.52 & 0.06 \\
\hline Active & 21.45 & 36.39 & & & & 27.05 & & & 25.52 & 41.91 & & & 31.05 & 29.43 & & \\
\hline Transport & (54.98) & $(82.62)$ & 1.68 & 0.21 & 33.17 (84.34) & $(54.72)$ & 0.69 & 0.08 & $(60.53)$ & (93.96) & 1.71 & 0.21 & $(79.99)$ & (61.07) & 0.18 & 0.02 \\
\hline
\end{tabular}

Note. ${ }^{*} \mathrm{p}<.05 ; * * \mathrm{p}<.01 ;{ }^{* * *} \mathrm{p}<.001$. 
Table 4

\section{Qualitative Themes and Illustrative Quotes}

\begin{tabular}{|c|c|}
\hline $\begin{array}{l}\text { Theme } \\
\text { (frequency) }\end{array}$ & Illustrative quotes \\
\hline \multicolumn{2}{|r|}{ Physical environment } \\
\hline $\begin{array}{l}\text { COVID-19 } \\
\text { closures } \\
\text { changed access } \\
(\mathrm{n}=110)\end{array}$ & $\begin{array}{l}\text { "I was working out at a public park that had trails and made it nice to work out outside, all parks are now closed where I live which } \\
\text { discouraged me for a while. I only have light kettle bells so I have been using them." (Non-Hispanic White Female) } \\
\text { "As someone who would normally go to the gym at least } 5 \text { times a week for powerlifting and bodybuilding, it's really annoying that the gym is } \\
\text { not considered an essential business. I only have a pull up bar at home and recently purchased some bands, so to say that things bave changed is } \\
\text { a big understatement. I can't squat anything like I normally would, have no way to deadlift, I can do pushups and pull-ups and other } \\
\text { bodyweight exercises. I rarely would do cardio normally, but I'm trying to do that more not as I can't walk. around campus anymore and } \\
\text { struggle to get moving enough otherwise." (Non-Hispanic White Male) }\end{array}$ \\
\hline $\begin{array}{l}\text { Has access to } \\
\text { resources for } \\
\text { PA }(n=45)\end{array}$ & $\begin{array}{l}\text { "If anything, I have become more physically active. When I'm at home I work on a farm with my family, in addition to the physical activity } \\
\text { schedule I kept when I was at school. Shutdown really hasn't impacted my life at all yet, since none of the activities I do are really social outside } \\
\text { of school." (Non-Hispanic White Female) } \\
\text { "Since remote learning I do not walk as much since not walking to class. I have been walking my dogs and will walk. for longer periods of time } \\
\text { with my family members that I currently am staying with. I have always done yoga. Since quarantine, many platforms have posted free videos so } \\
\text { I use these. I am lucky that my family has some weights and exercise equipment. I use these throughout the week, as well. Since being home, my } \\
\text { family will play games outside such as spikeball or baseball, which is activity I did not do at school. I feel that I am moving these throughout the } \\
\text { entire day but have spurts where I am very active. (Non-Hispanic White Female) }\end{array}$ \\
\hline $\begin{array}{l}\text { Neighborhood/ } \\
\text { residential } \\
\text { space as an } \\
\text { influence on } \\
\text { PA }(\mathrm{n}=32)\end{array}$ & $\begin{array}{l}\text { "My neighborhood is pretty remote and has no sidewalks. I haven't wanted to go outside much since the outbreak especially since so many other } \\
\text { neighbors are on the street, so I think this has hurt my activity level. Also, without classes and other activities to walk to, I have been very } \\
\text { sedentary. I do have a large yard, but that hasn't changed anything for me. Now, most days, I just sit in my dining room in the same chair } \\
\text { doing classes and work all day." (Non-Hispanic White Female) } \\
\text { "Where I live is very rural so unlike [college town], you can't walk everywhere and there are no sidewalks but there are parks you just bave to } \\
\text { drive there." (Non-Hispanic White Female) } \\
\text { "I have a fitness tracker that counts my steps. When I was at school I was between 10,000 and 15,000 steps a day. Since remote learning I } \\
\text { have been completing 2,500 to 5,000 steps a day. Lack. of motivation and fear running into people on the street has been burting my activity } \\
\text { level." (Non-Hispanic White Female) }\end{array}$ \\
\hline $\begin{array}{l}\text { Access to parks } \\
\text { and trails ( } \\
n=13 \text { ) }\end{array}$ & $\begin{array}{l}\text { "I take walks around parks (both local and state parks) more often. Now, there are no restaurants and few stores open, so going to parks is a } \\
\text { great reason to get out of the house. around outside and get sunlight after being cooped up all day inside." (Non-Hispanic White Female) } \\
\text { "My typical activity is gymnastics and there is really no way for me to safely participate in this activity in the current conditions. However, I } \\
\text { recently discovered a park. that has bars for pullups, dips, etc that i have been using after cleaning them well." (Non-Hispanic White } \\
\text { Female) }\end{array}$ \\
\hline $\begin{array}{l}\text { Lack of access } \\
\text { and resources } \\
(\mathrm{n}=92)\end{array}$ & $\begin{array}{l}\text { "I am no longer spending all day walking or sitting outside on campus and I am unable to play ice hockey. I also bad four jobs while on } \\
\text { campus, three of which had me moving and working regularly. Living on the fourth floor of my dorm encouraged me to take the stairs every day, } \\
\text { but now I live in a one story 'bouse' and have to stay inside." (Non-Hispanic Black Female) } \\
\text { "T have definitely become much less active. I don't possess many resources to be active at my home. I live in a very small house and have a small } \\
\text { yard so doing things inside or out is kind of difficult. I additionally am now not walking to class/ across campus, etc. so that is something that is } \\
\text { missing as well." (Non-Hispanic White Female) }\end{array}$ \\
\hline \multicolumn{2}{|r|}{ Social environment } \\
\hline Pets $(n=15)$ & $\begin{array}{l}\text { "Walking my dog has really given me a way to stay active but not having a walking commute decreased my level of activity by a large margin." } \\
\text { (Non-Hispanic White Female) } \\
\text { "I don't have to travel from class to class and I can't go to the gym. All I do is at home workouts and walk my dog and then sit at my desk the } \\
\text { rest of the day." (Non-Hispanic White Male) }\end{array}$ \\
\hline $\begin{array}{l}\text { Family/friends } \\
\text { to exercise with } \\
(\mathrm{n}=24)\end{array}$ & $\begin{array}{l}\text { "Managed to convince my dad to workout with me. Having a spotter made the "gainz" soar. Both hit our goal } 3 \text { weeks early for our PR } \\
\text { [personal record]." (Non-Hispanic White Male) } \\
\text { "T have definitely been more active since quarantine started. Now that I am living with parents, they make me work. out and walk. with them } \\
\text { almost every day so this has definitely been helpful!" (Asian American male) }\end{array}$ \\
\hline $\begin{array}{l}\text { Family/friends } \\
\text { as a barrier } \\
(\mathrm{n}=7)\end{array}$ & $\begin{array}{l}\text { "My family being around all the time has definitely been a hurtful factor along with not being able to exercise with friends." (Non-Hispanic } \\
\text { White Female) } \\
\text { "I have done more aerobic work, along with muscle training and yoga, but I have limited options for more intensive activity. Being around less } \\
\text { active family members has been particularly challenging." (Non-Hispanic White Female) }\end{array}$ \\
\hline $\begin{array}{l}\text { Lack of social } \\
\text { support for } \\
\text { exercise } \\
(n=190)\end{array}$ & $\begin{array}{l}\text { "Overall activity has gone down. Being alone in my apartment has hindered my motivation to be active." (Non-Hispanic White Male) } \\
\text { "No access to gyms, friends to work out with, low motivation to do anything at all have all decreased my physical activity." (Other, male) }\end{array}$ \\
\hline
\end{tabular}




\section{DISCUSSION}

The results of this study provide insight on the importance of the social and built (or structural) environment for encouraging and supporting PA for a population of college students during a unique time. As colleges look towards the future past the COVID-19 pandemic, it is essential to understand the role that PA can play in addressing the overall health concerns of students and how their surroundings can affect participation. The well documented physical and mental health benefits associated with regular PA participation underscore the importance of PA relative to preventing negative health outcomes throughout a stressful and challenging situation. Understanding the gender differences is insightful for tailoring strategies for changing behavior in the future.

Not surprisingly, the physical environment significantly influenced PA for the participating college students, which is consistent with other social ecological framework literature (Choi, Lee, Lee, Kang, \& Choi, 2017; Sallis et al., 2006). College campuses typically have extensive resources for students to engage in regular activity, from facilities that offer state-of-the-art fitness equipment and programming to clubs and intramural programs. Students typically have a plethora of opportunities to engage in activity during their time in college (Horacek et al., 2014). Campuses are typically pedestrian and cyclist friendly to facilitate walking and biking (Horacek et al., 2018; Horacek et al., 2012). Additionally, communities, cities, or towns where college campuses are located often are supportive of PA, especially active transportation (Molina-García, Menescardi, Estevan, Martínez-Bello, \& Queralt, 2019; Peachey \& Baller, 2015). Living in a generally resource-rich environment creates an opportunity for students to form active habits that were significantly challenged when the majority were removed from this positive space. This may present challenges for sustainable behaviors after graduation and resources may be harder to come by or financially inaccessible. The impact on PA for this population is similar to other studies that have examined activity levels during COVID-19 restrictions or confinement. In a large international study, Ammar et al. (2020) noted a negative effect on all PA intensity levels. Cancello, Soranna, Zambra, Zambon, and Invitti (2020) noted that young adults remained the most active relative to other age groups during lock-down in Italy but still declined. In line with our current results, in a population of Italian undergraduate students during lockdown, females experienced a greater PA decline than males during this period. Though neither of these studies were able to examine the impact of the environment on PA behavior. As previously noted, a study of undergraduate students in Spain, found that living situations during the lockdown period did influence PA participation, with those students remaining in university residence as the most active (Romero-Blanco et al., 2020). Though, contrary to our findings, students in the Romero-Blanco et al. (2020) study engaged in more activity during lockdown than before, and females were more active compared with males. Access to resources for PA may also be complicated by feelings of anxiety or fear of being in public and increasing the risk of contracting the virus. 
The role of social support was significant in the current study. This is consistent with the limited existing evidence. In a study of Canadian adults, it was noted that "having support for PA" was significantly associated with greater PA levels during the period of COVID-19 restrictions (Lesser \& Nienhuis, 2020). Other evidence pointed to similar relationships with the physical environment and PA during the early months of the pandemic. Data from several European and Middle Eastern countries showed that a lack of access to outdoor space, parks, and green space during "containment periods" impacted PA levels (Ugolini et al., 2020). Given the overall declines in PA participation seen during the pandemic, key influences on PA are important to understand to prevent future issues associated with inactivity, not only with college students but also the general population. There is risk of establishing new habits of higher sedentary behavior and less PA during a prolonged pandemic that could extend past this period. Combating this will necessitate the use of many resources, including a supportive physical and social environment, programs and policies to promote PA, and integration with multiple campus partners (e.g., health services, recreation, etc.).

The role of universities in addressing the physical and mental health as well as health behaviors of their students during remote learning is unclear. Most "best practices" have been established with a residential model in mind that provides structural environments with physical opportunities for students to be active. There are limited examples of effective strategies for delivering health and wellness programing for online students. The Exercise is Medicine on Campus $^{\text {TM }}$ (EIMOC) Initiative, which aims to promote PA and health throughout the campus community is poised to address some of these issues. Creative strategies from EIMOC programs can help to reach students no matter their location, providing encouragement and education about PA. Another strategy that universities can use to address inactivity and create supportive social environments for is through credited online PA class. Though the bulk of the literature has focused on in-person PA classes and positive outcomes (Lackman, Smith, \& McNeill, 2015; Quartiroli \& Maeda, 2016), some literature has suggested that online PA classes may also result in positive outcomes for PA as well (Sidman, Fiala, \& D'Abundo, 2011). Thus, offering a possible strategy for structuring a supportive PA environment for non-residential and off-campus students. A more complete assessment of the findings from this study regarding mental health and PA are found elsewhere (Wilson et al., 2021).

Although this study yielded a number of important findings there were some notable limitations. The volunteer sample may not be representative of all students at the institution of study, nor of university students in the United States. Our sample was drawn from health and wellness classes at the university which may have also resulted in a sample that was more aware of health and the importance of healthy behaviors. The self-report measures for PA used in this study, as with all self-report measures, may have issues associated with reliability and validity or resulted in poor recall of PA participation. Additionally, participants had to self-report about their environment, which may not have been accurate. Lastly, the cross-sectional study design limits the ability to make causal inferences about the relationship of the environment with PA in this population. Future studies could utilize longitudinal design and 
capitalize on access to more objective forms of PA assessments (e.g., fitness trackers) and the physical (e.g., audits) and social environments (e.g., social network analysis).

As universities plan for post-pandemic course delivery and the growth of online education, these findings can provide insight into the importance of considering how students' physical and social environments influence their PA, health behaviors, and outcomes. Although these findings are insightful for understanding PA behavior during an unprecedented era, there is opportunity to extrapolate and consider the implications for an evolving higher education landscape. Considering the important role of PA for physical and mental health, both acutely during the pandemic and long-term, it is essential to consider these insights for future PA interventions, strategies, and policies at universities. 


\section{REFERENCES}

Ammar, A., Brach, M., Trabelsi, K., Chtourou, H., Boukhris, O., Masmoudi, L., . . Hoekelmann, A. (2020). Effects of COVID-19 home confinement on eating behaviour and physical activity: Results of the ECLBCOVID19 international online survey. Nutrients, 12(6). https://doi.org/10.3390/nu12061583

Armstrong, T., \& Bull, F. (2006). Development of the World Health Organization Global Physical Activity Questionaire (GPAQ). Journal of Public Health 14(12), 66-70. https://doi.org/10.1007/s10389-006-0024-x

Barkley, J. E., Lepp, A., Glickman, E., Farnell, G., Beiting, J., Wiet, R., \& Dowdell, B. (2020). The acute effects of the COVID-19 pandemic on physical activity and sedentary behavior in university students and employees. International Journal of Exercise Science, 13(5), 1326-1339.

Bauman, A. E., Reis, R. S., Sallis, J. F., Wells, J. C., Loos, R. J., Martin, B. W., \& Lancet Phsyical Activity Series Working Group. (2012). Correlates of physical activity: Why are some people physically active and others not? Lancet, 380(9838), 258-271. https://doi.org/10.1016/S0140-6736(12)60735-1

Cancello, R., Soranna, D., Zambra, G., Zambon, A., \& Invitti, C. (2020). Determinants of the lifestyle changes during COVID-19 pandemic in the residents of northern Italy. International Journal of Environmental Research and Public Health, 17(17). https://doi.org/10.3390/ijerph17176287

Cerin, E., Saelens, B. E., Sallis, J. F., \& Frank, L. D. (2006). Neighborhood Environment Walkability Scale: Validity and development of a short form. Medicine and Science in Sports and Exercise, 38(9), 1682-1691. https://doi.org/10.1249/01.mss.0000227639.83607.4d

Choi, J., Lee, M., Lee, J. K., Kang, D., \& Choi, J. Y. (2017). Correlates associated with participation in physical activity among adults: A systematic review of reviews and update. BMC Public Health, 17(1), 356. https://doi.org/10.1186/s12889-017-4255-2

Creswell, J. W. (2007). Qualitative inquiry and research design (2nd ed.). Thousand Oaks, CA: Sage Publications.

Gallo, L. A., Gallo, T. F., Young, S. L., Moritz, K. M., \& Akison, L. K. (2020). The impact of isolation measures due to COVID-19 on energy intake and physical activity levels in Australian university students. Nutrients, 12(6). https://doi.org/10.3390/nu12061865

Gruber, K. J. (2008). Social support for exercise and dietary habits among college students. Adolescence, 43(171), 557575.

Horacek, T. M., Dede Yildirim, E., Kattelmann, K., Brown, O., Byrd-Bredbenner, C., Colby, S., .. White, A. (2018). Path analysis of campus walkability/bikeability and college students' physical activity attitudes, behaviors, and body mass index. American Journal of Health Promotion, 32(3), 578-586. https://doi.org/10.1177/0890117116666357 
Horacek, T. M., White, A. A., Byrd-Bredbenner, C., Reznar, M. M., Olfert, M. D., Morrell, J. S., ... ThompsonSnyder, C. A. (2014). PACES: a Physical Activity Campus Environmental Supports Audit on university campuses. American Journal of Health Promotion, 28(4), e104-117. https://doi.org/10.4278/ajhp.121212QUAN-604

Horacek, T. M., White, A. A., Greene, G. W., Reznar, M. M., Quick, V. M., Morrell, J. S., .. . Byrd-Bredbenner, C. (2012). Sneakers and spokes: An assessment of the walkability and bikeability of U.S. postsecondary institutions. Journal of Environmental Health, 74(7), 8-15; 2.

Jakovljevic, M., Bjedov, S., Jaksic, N., \& Jakovljevic, I. (2020). COVID-19 pandemia and public and global mental health from the perspective of global health security. Psychiatria Danubina, 32(1), 6-14. https://doi.org/10.24869/psyd.2020.6

Kaparounaki, C. K., Patsali, M. E., Mousa, D. V., Papadopoulou, E. V. K., Papadopoulou, K. K. K., \& Fountoulakis, K. N. (2020). University students' mental health amidst the COVID-19 quarantine in Greece. Psychiatry Research, 290, 113111. https://doi.org/10.1016/j.psychres.2020.113111

King, K. A., Vidourek, R. A., English, L., \& Merianos, A. L. (2013). Vigorous physical activity among college students: using the health belief model to assess involvement and social support. Archives of Exercise in Health and Disease, 4(2), 267-279.

Lackman, J., Smith, M. L., \& McNeill, E. B. (2015). Freshman college students' reasons for enrolling in and anticipated benefits from a basic college physical education activity course. Frontiers in Public Health, 3, 162. https://doi.org/10.3389/fpubh.2015.00162

Lesser, I. A., \& Nienhuis, C. P. (2020). The impact of COVID-19 on physical activity behavior and well-being of Canadians. International Journal of Environmental Research and Public Health, 17(11). https://doi.org/10.3390/ijerph17113899

Maher, J. P., Hevel, D. J., Reifsteck, E. J., \& Drollette, E. S. (2021). Physical activity is positively associated with college students' positive affect regardless of stressful life events during the COVID-19 pandemic. Psychology of Sport and Exercise, 52, 101826. https://doi.org/10.1016/j.psychsport.2020.101826

Molina-García, J., Menescardi, C., Estevan, I., Martínez-Bello, V., \& Queralt, A. (2019). Neighborhood built environment and socioeconomic status are associated with active commuting and sedentary behavior, but not with leisure-time physical activity, in university students. International Journal of Environmental Research and Public Health, 16(17). https://doi.org/10.3390/ijerph16173176

Peachey, A. A., \& Baller, S. L. (2015). Perceived built environment characteristics of on-campus and off-campus neighborhoods associated with physical activity of college students. Journal of American College Health, 63(5), 337-342. https://doi.org/10.1080/07448481.2015.1015027 
Physical Activity Guidelines Advisory Committee. (2018). 2018 Physical Activity Guidelines Advisory Committee Report. Washington DC: U.S. Department of Health and Human Services.

Quartiroli, A., \& Maeda, H. (2016). The Effects of a lifetime physical fitness (LPF) course on college students' health behaviors. International Journal of Exercise Science, 9(2), 136-148.

Romero-Blanco, C., Rodríguez-Almagro, J., Onieva-Zafra, M. D., Parra-Fernández, M. L., Prado-Laguna, M. D. C., \& Hernández-Martínez, A. (2020). Physical activity and sedentary lifestyle in university students: Changes during confinement due to the COVID-19 pandemic. International Journal of Environmental Research and Public Health, 17(18). https://doi.org/10.3390/ijerph17186567

Sallis, J. F., Cervero, R. B., Ascher, W., Henderson, K. A., Kraft, M. K., \& Kerr, J. (2006). An ecological approach to creating active living communities. Annual Review of Public Health, 27, 297-322. https://doi.org/10.1146/annurev.publhealth.27.021405.102100

Sallis, J. F., Grossman, R. M., Pinski, R. B., Patterson, T. L., \& Nader, P. R. (1987). The development of scales to measure social support for diet and exercise behaviors. Preventive Medicine, 16(6), 825-836. https://doi.org/10.1016/0091-7435(87)90022-3

Schuch, F. B., Bulzing, R. A., Meyer, J., Vancampfort, D., Firth, J., Stubbs, B., . . Smith, L. (2020). Associations of moderate to vigorous physical activity and sedentary behavior with depressive and anxiety symptoms in selfisolating people during the COVID-19 pandemic: A cross-sectional survey in Brazil. Psychiatry Research, 292, 113339. https://doi.org/10.1016/j.psychres.2020.113339

Sidman, C. L., Fiala, K. A., \& D'Abundo, M. L. (2011). Exercise motivation of college students in online, face-toface, and blended basic studies physical activity and wellness course delivery formats. Journal of American College Health, 59(7), 662-664. https://doi.org/10.1080/07448481.2010.524683

Talevi, D., Socci, V., Carai, M., Carnaghi, G., Faleri, S., Trebbi, E., . . Pacitti, F. (2020). Mental health outcomes of the CoViD-19 pandemic. Rivista di Psichiatria, 55(3), 137-144. https://doi.org/10.1708/3382.33569

The Chronicle of Higher Education. (2020). The Post-Pandemic College. Washington DC: The Chronicle of Higher Education.

Tison, G. H., Avram, R., Kuhar, P., Abreau, S., Marcus, G. M., Pletcher, M. J., \& Olgin, J. E. (2020). Worldwide effect of COVID-19 on physical activity: A descriptive study. Annals of Internal Medicine, 173(9), 767-770. https://doi.org/10.7326/m20-2665

Ugolini, F., Massetti, L., Calaza-Martínez, P., Cariñanos, P., Dobbs, C., Ostoic, S. K., . . Sanesi, G. (2020). Effects of the COVID-19 pandemic on the use and perceptions of urban green space: An international exploratory study. Urban Forestry \& Urban Greening, 56, 126888. https://doi.org/10.1016/j.ufug.2020.126888 
Wathelet, M., Duhem, S., Vaiva, G., Baubet, T., Habran, E., Veerapa, E., . . D'Hondt, F. (2020). Factors associated with mental health disorders among university students in france confined during the COVID-19 pandemic. JAMA Network Open, 3(10), e2025591. https://doi.org/10.1001/jamanetworkopen.2020.25591

Wilson, O. W. A., Papalia, Z., Duffey, M., \& Bopp, M. (2019). Differences in college students' aerobic physical activity and muscle-strengthening activities based on gender, race, and sexual orientation. Preventive Medicine Reports, 16, 100984-100984. https://doi.org/10.1016/j.pmedr.2019.100984

Wilson, O. W. A., Holland, K. E., Elliott, L. D., Duffey, M., \& Bopp, M. (2021). The Impact of the COVID-19 Pandemic on US College Students' Physical Activity and Mental Health. Journal of Physical Activity and Health, 18(3), 272. https://doi.org/10.1123/jpah.2020-0325

World Health Organization. (2020). WHO coronavirus disease (COVID-19) dashboard. Retrieved from https://covid19.who.int/

Address Author correspondence to:

Melissa Bopp, Ph.D., FACSM (she/her)

The Pennsylvania State University

268R Recreation Building University Park, PA 16802

email: mjb73@psu.edu 